11

\title{
Использование пленок из многослойного графена в качестве покрытий светоизлучающих GaAs-структур
}

\author{
() А.В. Алафрердов ${ }^{1,2,3}$, О.В. Вихрова ${ }^{1}$, Ю.А. Данилов ${ }^{1}$, Б.Н. Звонков ${ }^{1}$, С.А. Мошкалев ${ }^{2}$ \\ ${ }^{1}$ Научно-исследовательский фризико-технический институт Нижегородского университета им. Н.И. Лобачевского, \\ 603950 Нижний Новгород, Россия \\ ${ }^{2}$ Center for Semiconductor Components and Nanotechnologies, University of Campinas, \\ 13083-870 Campinas, SP, Brazil \\ ${ }^{3}$ The „Gleb Wataghin“ Institute of Physics, University of Campinas, \\ 13083-859 Campinas, SP, Brazil \\ e-mail: danilov@nifti.unn.ru
}

Поступила в редакцию 06.11.2019 г.

В окончательной редакции 06.11.2019 г.

Принята к публикации 26.11.2019 г.

\begin{abstract}
Экспериментально обнаружено существенное (почти на два порядка величины) увеличение интенсивности фото- и электролюминесценции диодной структуры с квантовой ямой $\mathrm{InGaAs} / \mathrm{GaAsSb} / \mathrm{GaAs}$, слоем GaMnAs в качестве спинового инжектора и контактным покрытием из пленки многослойного графена. Результат объясняется возможным образованием гибридной системы многослойного графена и полупроводника GaAs под воздействием излучения Не-Ne-лазера, приводящим к изменению зонной диаграммы гетероструктуры.
\end{abstract}

Ключевые слова: светоизлучающая структура, $\mathrm{GaAs}$, квантовая яма, многослойный графен, люминесценция, лазерное воздействие.

DOI: $10.21883 /$ OS.2020.03.49067.300-19

\section{Введение}

Светоизлучающие полупроводниковые приборы на основе $\mathrm{GaAs}$, содержащие в качестве активной области двуслойные квантовые ямы типа InGaAs/GaAsSb/GaAs, являются перспективными для использования в ближнем инфракрасном диапазоне, в частности, в волоконнооптических линиях связи [1]. Излучательные переходы в этих гетероструктурах являются пространственно непрямыми и реализуются между основными состояниями электронов в InGaAs и дырок в GaAsSb. Допускается интеграция светоизлучающей структуры на $\mathrm{Si}$-подложке ввиду прозрачности кремния по отношению к излучению двуслойных ям указанного вида [1]. Интересное расширение функциональных возможностей структур с двуслойными квантовыми ямами возникает при введении слоя магнитного полупроводника GaMnAs, выполняющего роль инжектора спин-поляризованных носителей тока [2]: излучение оказывается частично циркулярнополяризованным, причем степень поляризации определяется знаком и величиной внешнего магнитного поля. Отметим особенность указанных гетероструктур: интенсивность люминесценции существенно зависит от изгиба зон в области двуслойной ямы, который меняется при введении в приповерхностную область дельталегированного слоя акцепторной примеси (в частности, $\mathrm{Mn}$ [3]). В связи с совершенствованием параметров гетероструктур для приборных применений представляет интерес использование покрытий, например, графена $[4,5]$.
Наряду с однослойным графеном многослойный графен (МСГ), иногда называемый сверхтонким графитом, тоже привлекает достаточно много внимания. МСГ не сильно уступает по своим электрическим, оптическим и термическим свойствам однослойному графену, методы его получения являются достаточно простыми и масштабируемыми, и поэтому он представляет собой перспективный материал для электроники будущего.

В настоящей работе представлены результаты исследования возможности использования пленок МСГ в качестве проводящего и пассивирующего покрытия светоизлучающих структур на основе GaAs c двуслойной квантовой ямой и слоем GaMnAs в качестве спинового инжектора.

\section{Методика эксперимента}

Для изготовления активной части структур использовали метод МОС-гидридной эпитаксии (МОСГЭ) при атмосферном давлении. Процесс МОСГЭ проводился в потоке водорода в горизонтальном реакторе с использованием в качестве источников компонентов арсина и металлорганических соединений (триметилгаллия, триметилиндия и триметилсурьмы). Подложки представляли собой пластины $n^{+}-\mathrm{GaAs}(100)$, легированные теллуром. Вначале при температуре процесса $\left(T_{g}\right)$, равной $650^{\circ} \mathrm{C}$, формировался буферный слой GaAs толщиной $0.3-0.4 \mu \mathrm{m}$, легированный $\mathrm{Si} \mathrm{c}$ концентрацией $\sim 10^{17} \mathrm{~cm}^{-3}$. Далее $T_{g}$ понижалась до $560^{\circ} \mathrm{C}$, и выращивалась двуслойная кванто- 
Технологические параметры серии гетеронаноструктур $\mathrm{GaAs} / \mathrm{In}_{x} \mathrm{Ga}_{1-x} \mathrm{As} / \mathrm{GaAs}_{1-y} \mathrm{Sb}_{y} / \mathrm{GaAs} \quad(x=0.1-0.12$, $y=0.15-0.17) \quad$ с инжектирующим слоем GaMnAs, изготовленных на пластинах $n^{+}$-GaAs (100)

\begin{tabular}{c|c|c|c|c|c}
\hline $\begin{array}{c}\text { № } \\
\text { структуры }\end{array}$ & $\begin{array}{c}h_{\mathrm{GaAsSb}}, \\
\mathrm{nm}\end{array}$ & $\begin{array}{c}h_{\text {InGaAs, }} \\
\mathrm{nm}\end{array}$ & $Y_{\mathrm{Mn}}$ & $\begin{array}{c}d_{s}, \\
\mathrm{~nm}\end{array}$ & $\begin{array}{c}T_{g}(\mathrm{QW}), \\
{ }^{\circ} \mathrm{C}\end{array}$ \\
\hline 7969 & 8 & 6 & 0.13 & $16-20$ & 560 \\
7971 & 8 & 6 & 0.13 & $8-10$ & 560 \\
7975 & - & - & 0.13 & - & -
\end{tabular}

вая яма $\operatorname{In}_{x} \mathrm{Ga}_{1-x} \mathrm{As} / \mathrm{GaAs}_{1-y} \mathrm{Sb}_{y}$ (с толщинами слоев 6 и $8 \mathrm{~nm}$ соответственно и составом $x=0.1-0.12$, $y=0.15-0.17)$. В аналогичных условиях формировался спейсерный слой $\mathrm{GaAs}\left(d_{s}\right)$ толщиной 8-20 nm (таблица). После этого температура выращивания уменьшалась до $350^{\circ} \mathrm{C}$, давление в реакторе понижалось до 25-50 Torr, и поочередным распылением импульсным лазером металлической $(\mathrm{Mn})$ и полупроводниковой (GaAs) мишеней в потоке водорода и арсина формировался слой GaMnAs (выполняющий роль спинового инжектора) толщиной порядка $100 \mathrm{~nm}$. Эпитаксиальный рост завершался созданием покровного нелегированного слоя $\mathrm{GaAs}$ толщиной около $10 \mathrm{~nm}$ (также методом импульсного лазерного нанесения). Содержание марганца в слое GaMnAs оценивалось по формуле $Y_{\mathrm{Mn}}=t_{\mathrm{Mn}} /\left(t_{\mathrm{Mn}}+t_{\mathrm{GaAs}}\right)$ (где $t_{\mathrm{Mn}}$ и $t_{\mathrm{GaAs}}$ - времена распыления мишеней марганца и арсенида галлия) и составляло 0.13. Образец 7975 (таблица) представлял собой слой GaMnAs, выращенный на подложке полуизолирующего GaAs, и использовался для контроля электрических (при $T=300 \mathrm{~K}$ подвижность и слоевая концентрация основных носителей заряда - дырок - имели следующие значения: $\mu_{\mathrm{ef}}=33 \mathrm{~cm}^{2} / \mathrm{Vs}, p_{s}=7.8 \cdot 10^{13} \mathrm{~cm}^{-2}$ ) и гальваномагнитных свойств GaMnAs.

Необходимо отметить, что указанные выше условия выращивания ферромагнитного полупроводника GaMnAs были выбраны на основании ряда проведенных ранее экспериментальных исследований [6,7]. Основное внимание было уделено сохранению высокого кристаллического качества слоев при достижении максимально большого значения температуры фазового перехода ферромагнетик-парамагнетик. Критерием выбора толщины слоев являлись сохранение достаточно гладкой поверхности структуры и минимальное количество дефектов на границе раздела „ферромагнитный полупроводник/обычный полупроводник“. В случае выращивания GaMnAs в указанных выше технологических условиях (температура, содержание примеси) достаточно гладкая поверхность слоев сохранялась вплоть до толщины слоя $\sim 100 \mathrm{~nm}$. Тонкий $(10 \mathrm{~nm})$ покровный слой GaAs, представляющий собой так называемый низкотемпературный арсенид галлия, по существу не изменяет морфологию структуры.
Для получения покрытий из МСГ (пленок МСГ на поверхности покровного слоя $\mathrm{GaAs}$ ) использовался модифицированный метод Ленгмюра-Блоджетт [8]. Исходным материалом для пленок служила суспензия МСГ, полученная методом расслаивания графита в жидкой фазе под действием ультразвуковой обработки [8-10].

Для исследования характеристик структур были использованы растровая электронная микроскопия с помощью системы Nova 200 Nanolab, FEI; спектроскопия комбинационного рассеяния (установка NT-MDT Ntegra Spectra с лазером на длине волны $473 \mathrm{~nm}$ ).

Излучательные свойства структур изучались при температуре $T_{m}=77 \mathrm{~K}$. Возбуждение фотолюминесценции

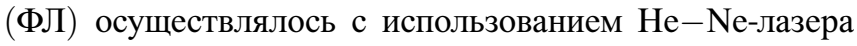
(длина волны излучения $632.5 \mathrm{~nm}$, мощность $30 \mathrm{~mW}$ ). Для наблюдения электролюминесценции (ЭЛ) выкалывались образцы структур размером $1.5 \times 2.5 \mathrm{~mm}$. Омический контакт к подложке $n^{+}$-GaAs формировался электроискровым вжиганием оловянной фольги. Контакт к поверхности слоев МСГ/GaAs был прижимной. ЭЛ-излучение собиралось с лицевой стороны структур. Спектры ЭЛ измерялись в режиме прямого смещения диодов. Эти же образцы были использованы для исследования вольтамперных характеристик (BAX) диодов.

\section{Экспериментальные результаты и обсуждение}

Были получены образцы диодных структур 7969 и 7971 с двуслойной квантовой ямой и с различным числом нанесений пленок МСГ. Стандартными были следующие условия формирования графеновых пленок: начальная площадь водяного зеркала $\sim 12 \mathrm{~cm}^{2}$, коэффициент уплотнения пленки $\sim 2$, объем суспензии, используемый при однократном нанесении, равен $0.35 \mathrm{ml}$ (с концентрацией $\sim 0.3 \mathrm{mg} / \mathrm{ml})$. Число нанесений составляло одно или три. Из анализа изображений, полученных на растровом электронном микроскопе (РЭМ), было установлено, что после однократного нанесения плотность покрытия подложки пленкой составляет $\sim 50$, а после трехкратного нанесения $\sim 95 \%$. При этом слоевое сопротивление пленки МСГ уменьшается от $1600 \mathrm{Ohm} / \mathrm{sq}$ (однократное нанесение) до $150 \mathrm{Ohm} / \mathrm{sq}$ (трехкратное нанесение). То есть при трехкратном нанесении пленка является практически сплошной (рис. 1) с приемлемым для приборных применений сопротивлением. Как показано в $[8,10]$, отдельные пластины МСГ имеют следующие размеры: ширина $1-5 \mu \mathrm{m}$, длина $10-50 \mu \mathrm{m}$ и толщина 5-50 nm. Таким образом, пленку из МСГ после однократного нанесения можно представить как массив графеновых нанополосок, одна часть которых прилегает к верху подложки, не закрывая полностью поверхность, а другая может частично накладываться на нанополоски МСГ нижнего уровня. При трехкратном нанесении незакрытая поверхность подложки практически исчезает, а наложение пластин МСГ друг на друга увеличивается, 


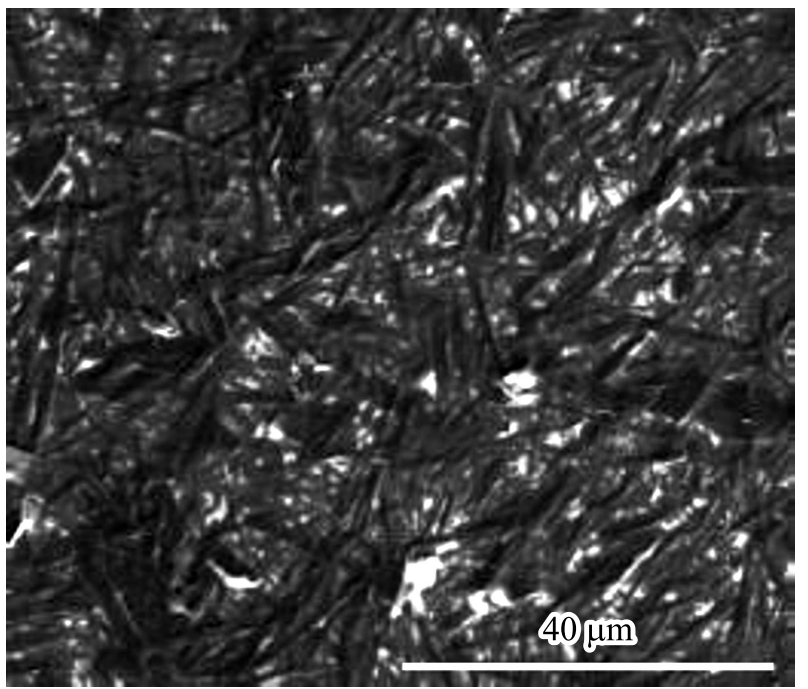

Рис. 1. РЭМ-изображение пленки из МСГ, нанесенной трехкратно методом Ленгмюра-Блоджетт. Масштабная линейка $40 \mu \mathrm{m}$.

в результате чего пленка может представлять собой хаотическое нагромождение пластин МСГ с некоторым вкладом воздушных прослоек и, может быть, остатков растворителя (последнее менее вероятно из-за испарения растворителя при хранении на воздухе).

Нанесение пленки графена вызвало изменения ВАХ структур 7969 и 7971. В частности, для структуры 7969 по сравнению с исходной ВАХ (рис. 2, кривые 1) после однократного нанесения пленки МСГ на поверхность наблюдалось уменьшение обратного тока и снижение наклона ВАХ в прямой ветви, что соответствует увеличению последовательного сопротивления. После трехкратного нанесения (рис. 2, кривые 2) наблюдалось дальнейшее уменьшение обратного тока и некоторое снижение последовательного сопротивления. Это согласуется с вышеупомянутыми данными по слоевому сопротивлению пленок МСГ и его изменению с ростом числа нанесений. Для структуры 7971 изменения ВАХ при нанесении пленок МСГ аналогичны. Дальнейшие изменения в BAX происходят в результате воздействия измерительных операций.

Исходные образцы структур 7969 и 7971 (не содержащие пленок МСГ на поверхности) и образцы, на поверхность которых было произведено одно или три нанесения этих пленок, для измерений ФЛ были помещены на кварцевом держателе в сосуд Дьюара с жидким азотом. После воздействия лазерного излучения с длиной волны $632.5 \mathrm{~nm}$ и мощностью $30 \mathrm{~mW}$ (площадь пятна $0.25 \mathrm{~mm}^{2}$ ) в течение нескольких секунд внешний вид образцов структур 7969 и 7971 с МСГ на поверхности модифицировался: визуально поверхность в месте экспозиции $\mathrm{He}-\mathrm{Ne}$-лазером потемнела. При последующем исследовании спектров ФЛ дальнейшее воздействие лазера в течение приблизительно $10 \mathrm{~min}$ уже не приводило к изменению внешнего вида структур. Наблюдаемый эффект наиболее ярко проявился для случая, когда поверхность структур была закрыта пленкой МСГ с трехкратным нанесением.

Результаты исследования ФЛ гетероструктур 7969 и 7971 представлены на рис. 3. Можно видеть, что основным результатом нанесения пленок графена на поверхность структуры 7969 является существенное, до двух порядков величины (рис. 3,a, кривые 2 и 3), увеличение интенсивности пика ФЛ при энергии кванта $\sim 1.3 \mathrm{eV}$, обусловленного непрямыми излучательными переходами в квантовой яме между зоной проводимости слоя InGaAs и валентной зоной слоя GaAsSb, по отношению к спектру исходного (не покрытого пленкой МСГ) образца (рис. 3, $a$, кривая 1). При этом интенсивность пика, отвечающего межзонным переходам в GaAs $(1.508 \mathrm{eV})$, увеличивается не более чем на порядок величины. Наблюдаемое изменение положения пика ФЛ (1.335 eV на исходном образце и $1.320 \mathrm{eV}$ после трехкратного нанесения графена), вероятнее всего, связано с разбросом параметров квантовых ям в исходной
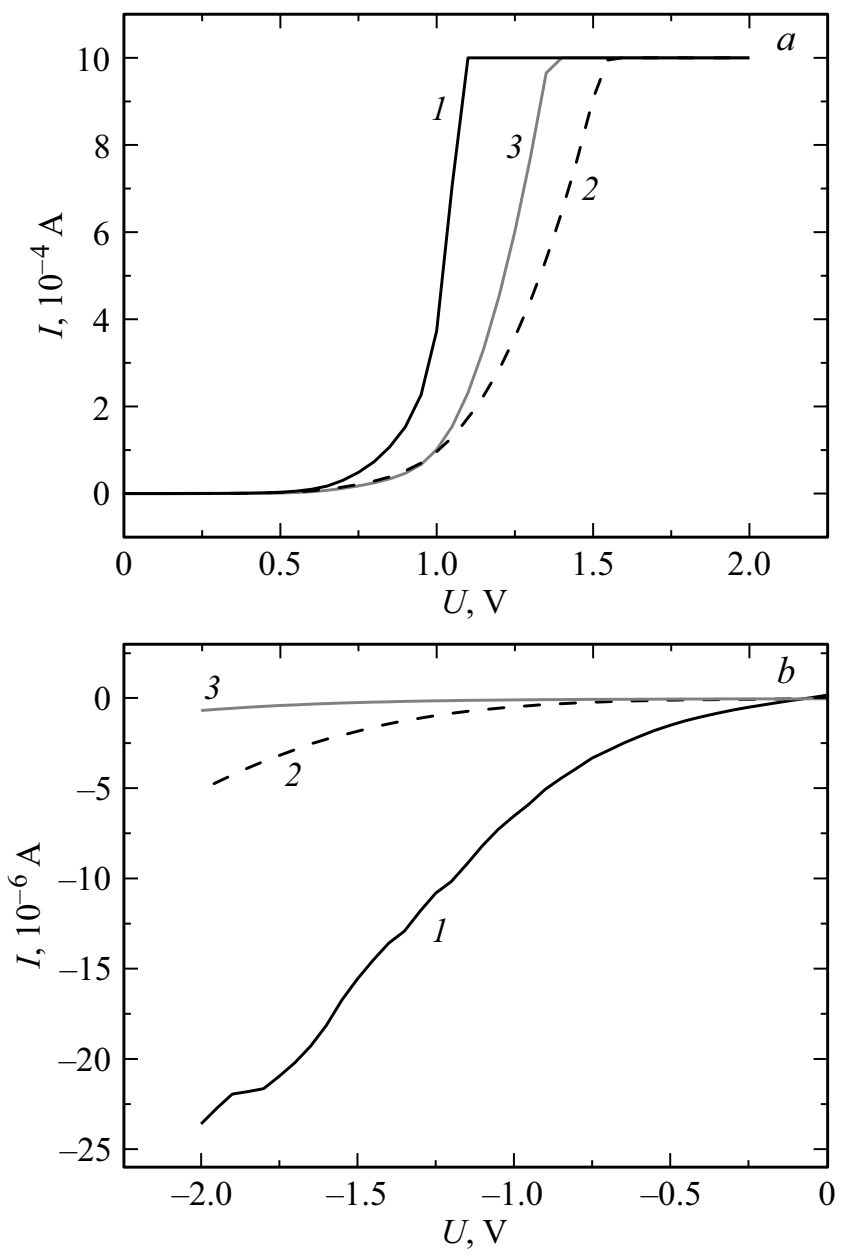

Рис. 2. ВАХ структуры 7969: 1 - исходный образец, 2 после нанесения на поверхность 1 слоя пленки МСГ, 3 после нанесения 3 слоев графена. На рисунке представлены прямая $(a)$ и обратная $(b)$ ветки соответственно. $T=300 \mathrm{~K}$. 

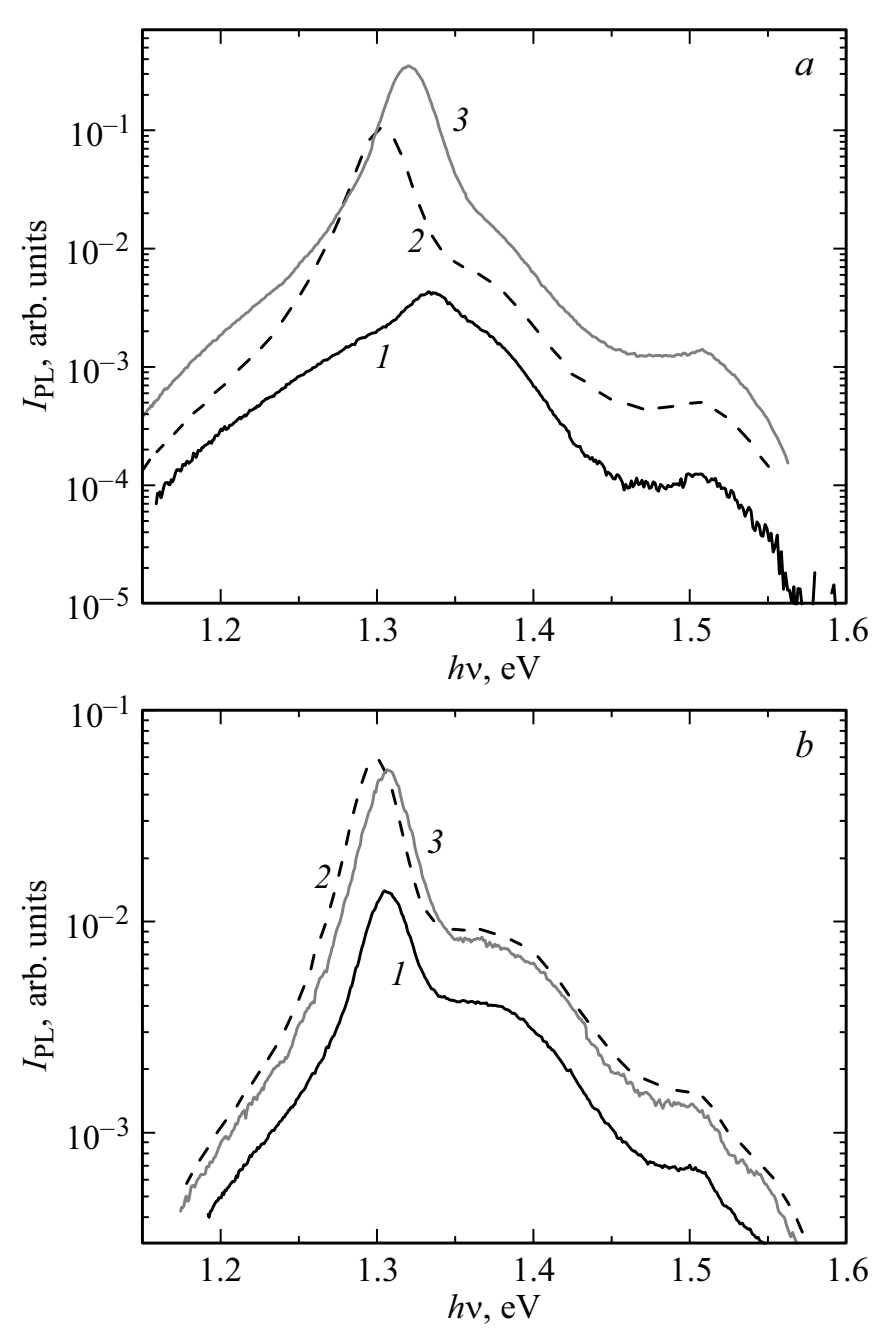

Pис. 3. (a) Спектры ФЛ структуры 7969 при температуре 77 К: 1 - исходный образец, 2 - после нанесения на поверхность 1 слоя пленки МСГ, 3 - после нанесения 3 слоев пленки МСГ. (b) Спектры ФЛ структуры 7971 при температуре 77 К: 1 исходный образец, 2 - после нанесения на поверхность 1 слоя пленки МСГ, 3 - после нанесения 3 слоев пленки МСГ.

пластине. Для структуры 7971 в результате нанесения пленки графена также наблюдалось (рис. $3, b$, кривые 2 и 3 ) увеличение интенсивности ФЛ в области квантовой ямы приблизительно в 5 раз по сравнению с исходной (без пленки графена - рис. $3, b$, кривая 1 ). Изменений положения пика излучения не замечено.

Обратим внимание на то, что в результате воздействия $\mathrm{He}-\mathrm{Ne}$-лазера, применяемого при измерении ФЛ, на поверхность структур в среде жидкого азота в течение порядка $10 \mathrm{~min}$ изменились и их ВАХ. Результаты измерений ВАХ для структуры 7969 с трехкратным нанесением пленки МСГ, подвергнутой воздействию лазера, показали, что облучение лазером привело к снижению последовательного сопротивления и существенному уменьшению обратных токов по сравнению со структурой с только что нанесенной пленкой графена.
Спектры ЭЛ структуры 7969 при токе накачки $1 \mathrm{~mA}$ приведены на рис. 4. Образцы для исследования ЭЛ площадью $\sim 3.7 \mathrm{~mm}^{2}$ выкалывались из образцов, прошедших процедуру измерения спектров ФЛ (что эквивалентно воздействию $\mathrm{He}-\mathrm{Ne}$-лазера с указанными выше параметрами). При этом область, подвергнутая лазерному воздействию, располагалась в центре образца. Из рис. 4 видно, что нанесение пленки из МСГ и его модификация посредством воздействия излучения $\mathrm{He}-\mathrm{Ne}$-лазера приводит, так же как и в исследованиях ФЛ, к увеличению интенсивности ЭЛ-излучения от квантовой ямы не менее чем на порядок величины по сравнению с исходной (не содержащей пленки графена) структурой. Наблюдаемый сдвиг положения пика ЭЛ от $1.338 \mathrm{eV}$ в исходном образце до $1.308 \mathrm{eV}$ в структурах, покрытых графеном, также может быть связан с разбросом параметров квантовых ям по выращенной пластине. Увеличение тока накачки до 4 и $10 \mathrm{~mA}$ вызывает только увеличение интенсивности ЭЛ и не приводит к изменениям в соотношении интенсивностей исходного образца и образцов с нанесенным графеном.

Ясно, что воздействие $\mathrm{He}-\mathrm{Ne}$-лазера на образец, погруженный в жидкий азот, в процессе измерения ФЛ приводит к модифицированию поверхности структур, покрытых пленкой МСГ. Следовательно, представляется важным исследование изменений морфологии поверхности покрытых графеном структур, происходящих при воздействии на них лазерного излучения. На рис. 5, $a$ показано полученное с помощью растрового электронного микроскопа изображение поверхности структуры 7971 в области, подвергнутой воздействию $\mathrm{He}-\mathrm{Ne}$-лазера. Во-первых, отметим, что диаметр модифицированной области $(\sim 3 \mathrm{~mm})$ превышает размер лазерного пучка (диаметром $\sim 0.5 \mathrm{~mm}$ ). Во-вторых, по сравнению с краями центральная область выглядит „голой“ (рис. 5, a). На

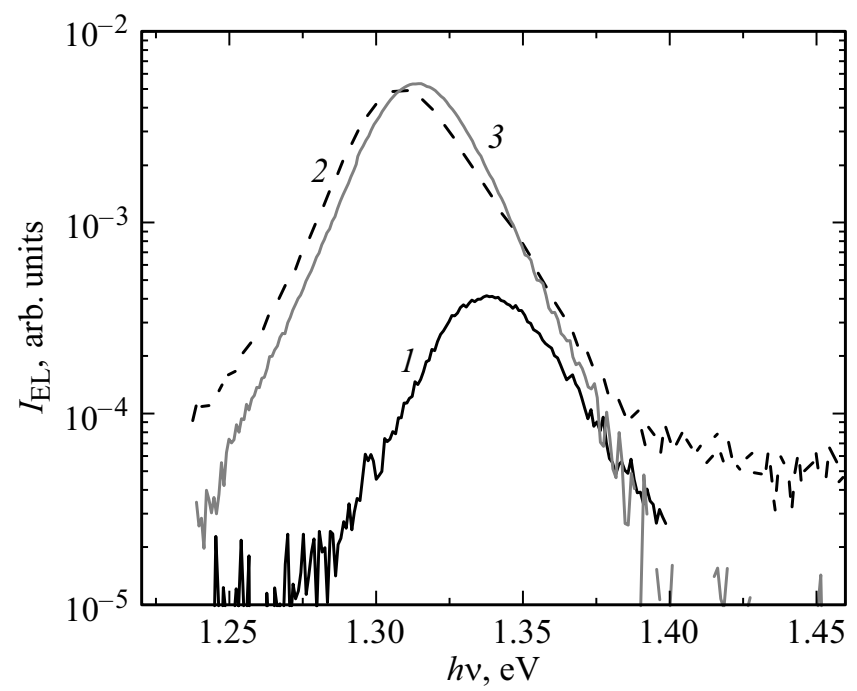

Рис. 4. Спектры ЭЛ структуры 7969 при температуре 77 К, величина тока $1 \mathrm{~mA}: 1$ - исходный образец, 2 - после нанесения на поверхность 1 слоя пленки МСГ, 3 - после нанесения 3 слоев пленки МСГ. 

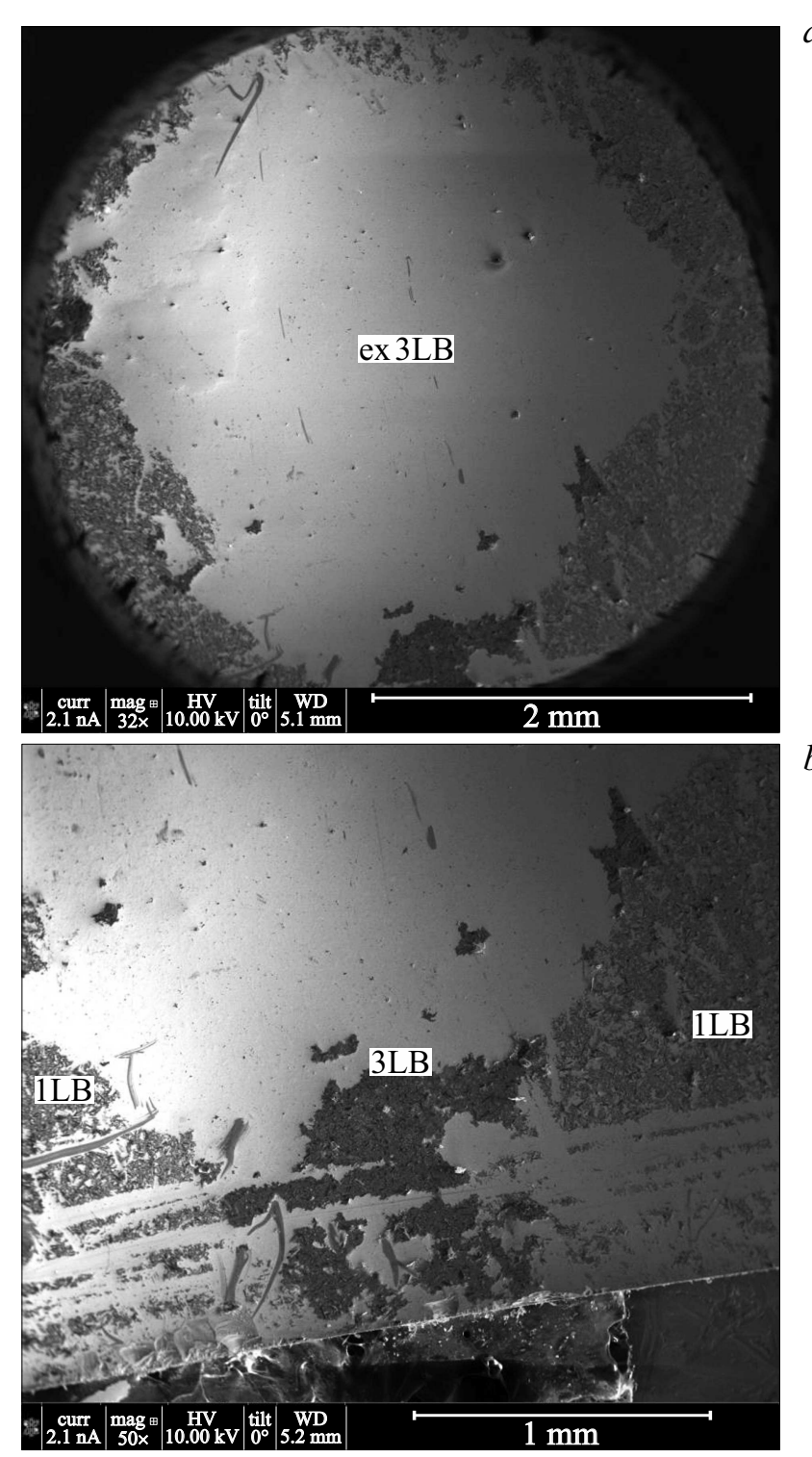

Рис. 5. (a) РЭМ-изображение области структуры 7971 с трехкратным нанесением пленки графена после воздействия лазерного излучения $\mathrm{He}-\mathrm{Ne}$-лазера в течение нескольких секунд в процессе измерения спектров ФЛ в жидком азоте. (b) РЭМ-изображение области структуры 7971 вблизи края модифицированной области, где отмечены участки с трехкратным нанесением (3LB) и с более тонким, подобным однократному нанесению (1LB).

краях модифицированной области отмечаются участки как с трехкратным нанесением (на рисунке они обозначены как 3LB), так и более тонкие, подобные однократному нанесению (обозначен как 1LB) (рис. 5, b).

На рис. 6 показаны при большем увеличении РЭМизображения морфологии поверхности структуры, на которую трехкратно была нанесена пленка МСГ, после ее модифицирования лазером (область на рисунке обозначена как ех 3LB). Исследование при увеличении $50000 \times$ (рис. 6, b) позволило наблюдать объекты длиной более $2 \mu \mathrm{m}$ и шириной около $300 \mathrm{~nm}$, которые мы интерпретировали как „тени“ полосок МСГ в этой модифицированной области. Обращает на себя внимание зернистый вид области, находившейся под воздействием лазера (размер неоднородностей $\approx 70 \mathrm{~nm}$ ).

Методом спектроскопии комбинационного рассеяния света (КРС) были также проведены исследования модифицированных лазером двух областей структуры 7971: там, где визуально не наблюдаются полоски МСГ, а есть лишь их следы („тени“ - см. выше, спектр 1 на рис. 7), и области расположения разрозненных частичек, напоминающих полоски МСГ (спектр 2 на рис. 7). От разрозненных частичек наблюдается спектр, характерный для полосок МСГ. Положения наиболее интенсивных пиков КРС таковы: 1351, 1563 и $2706 \mathrm{~cm}^{-1}$.
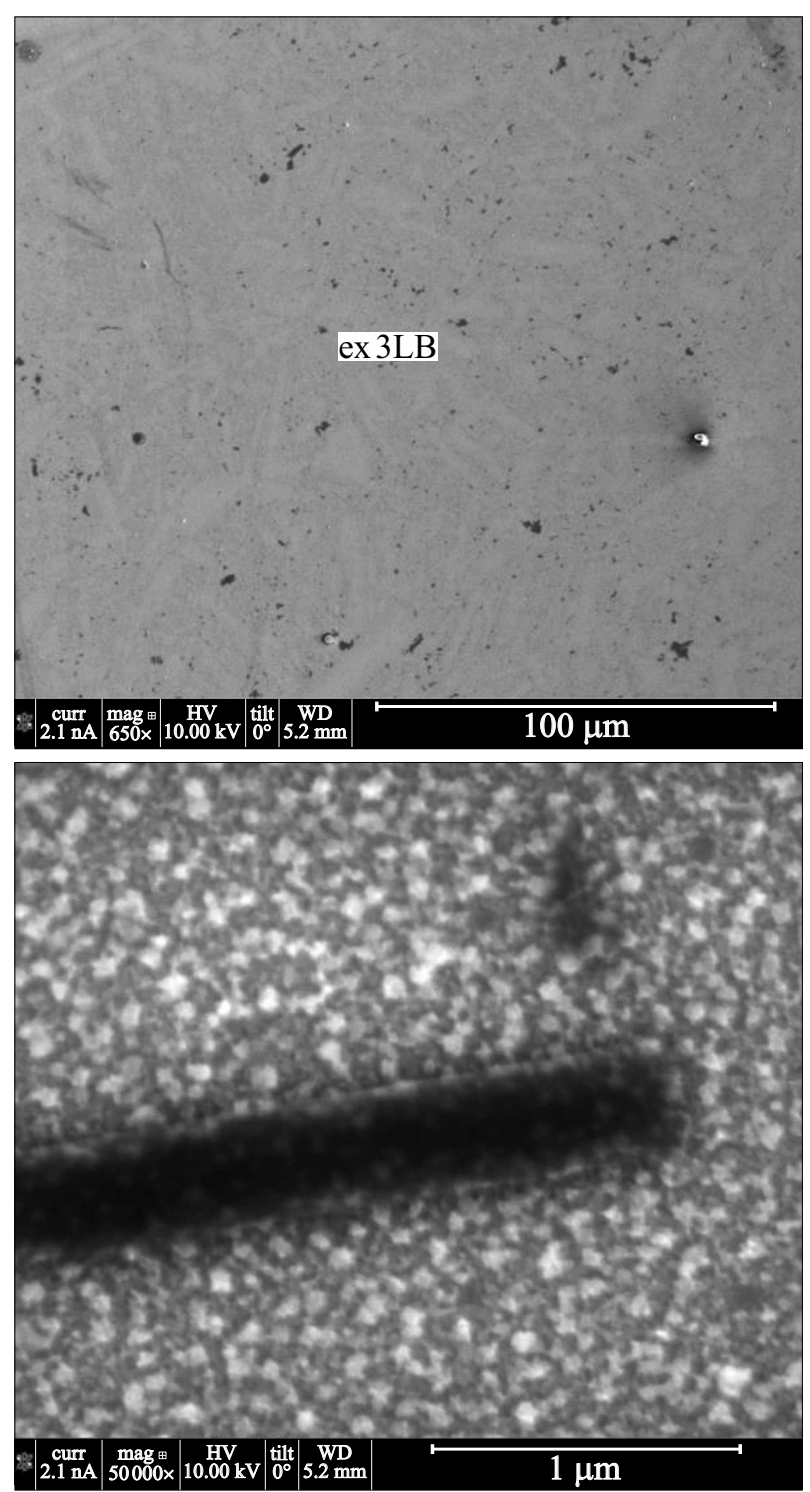

Рис. 6. РЭМ-изображение структуры 7971 с трехкратным нанесением пленки графена в центре области облучения лазером: $(a)$ масштаб линейки $100 \mu \mathrm{m}$; $(b)$ масштаб линейки $1 \mu \mathrm{m}$. 


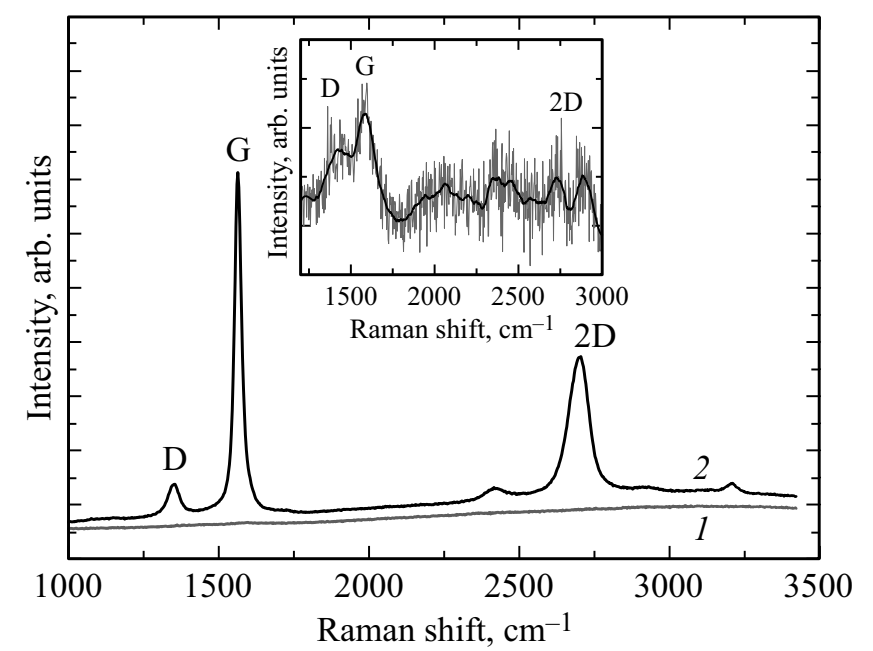

Рис. 7. Спектры комбинационного рассеяния структуры 7971, измеренные в двух точках модифицированной в результате лазерного воздействия области: там, где визуально не наблюдаются полоски многослойного графена (спектр 1) и от разрозненных частичек, напоминающих полоски многослойного графена (спектр 2). Температура измерений $300 \mathrm{~K}$. На вставке приведен спектр, полученный в результате вычитания фонового сигнала из спектра 1.

Эти пики отмечены на рис. 7 принятыми в литературе обозначениями D, G и 2D соответственно. Положения пиков зависят от длины волны зондирующего лазера и температуры изучаемого объекта. Экспериментально определенные нами значения положения этих пиков соответствуют значениям, характерным для структур, нагретых (локально) до более чем $1000^{\circ} \mathrm{C}[9,11,12]$. Отметим, что наличие пика D указывает как на присутствие дефектов в графене, так и на наличие краевых областей с оборванными связями [13]. Пик $\mathrm{G}$ связан с наличием в углеродной структуре межатомных $s p^{2}$ связей, а его положение практически не зависит от количества слоев в графене [11]. Отношение интенсивностей пиков $\mathrm{D}$ и $\mathrm{G}$ в определенной степени характеризует разупорядочение углеродной структуры. Для спектра 2 на рис. 7 отношение $I(\mathrm{D}) / I(\mathrm{G}) \approx 0.09$.

Полоса 2D является обертоном (второго порядка) линии D. Для однослойного графена пик $2 \mathrm{D}-$ резкий и примерно в 4 раза более интенсивный, чем пик G. При увеличении числа слоев в графене полоса 2D уширяется, и при числе слоев более 5 спектр КРС подобен спектру графита, который состоит из двух компонентов 2D 1 и $2 \mathrm{D}_{2}$, интенсивности которых составляют приблизительно 0.25 и 0.5 от высоты пика $G$ соответственно. Пик $2 \mathrm{D}_{2}$ перемещается в сторону больших значений сдвига КРС относительно пика 2D графена. Экспериментальное значение отношения интенсивностей пиков 2D и $\mathrm{G}$ для спектра, приведенного на рис. 7 (кривая 2), составляет 0.41 .

В спектре КРС для случая, когда не видны нанополоски графена (рис. 7, спектр 1), сигнал от них практически отсутствует. Математическая обработка спектра 1, а именно вычитание фонового сигнала, позволила получить спектр комбинационного рассеяния, показанный на вставке к рис. 7. С уверенностью можно полагать, что в спектре присутствуют пики D и G, но линия 2D трудно различима на фоне шума. Наличие подобного спектра комбинационного рассеяния в области, где визуально полоски многослойного графена не наблюдаются, а есть только „следы“, может быть связано и с аппаратными ограничениями используемой установки комбинационного рассеяния. В частности, при выборе параметров записи спектра использовали максимальную мощность лазера и короткое время записи $10 \mathrm{~s}$, что могло просто создать эффект отжига для тонких (1-3 слоя пленок МСГ) пластин графена [12,14].

Возможны два варианта модификации центральной области: либо пленка графена отслоилась после воздействия лазерной засветки в среде жидкого азота, либо пленка графена „сплавилась“ с GaAs и образовала сплошное покрытие-композит. В пользу второго варианта свидетельствует наблюдение „теней“ полосок графена в этой модифицированной области (рис. 6). Возможно, зернистый вид области, находившейся под воздействием лазера, и указывает на образование углеродного композита на поверхности GaAs.

Вероятнее всего, происходят оба указанных процесса. При погружении в азот и лазерной засветке области с 3 нанесениями часть полосок графена действительно отслоилась. Наличие „теней“ этих полосок в засвеченной лазером области можно трактовать либо как просто след (изменение поверхности) после "отслоившихся"полосок, либо как формирование покрытия из очень тонких (1-3 графеновых слоя) пластин графена, которые образовались при расслоении в результате воздействия жидкого азота и лазерного излучения. При этом верхняя часть покрытия с тремя нанесениями (более массивная) отвалилась, а нижняя часть (1-3 слоя МСГ), имеющая предположительно хорошую адгезию с подложкой, осталась на ней.

Наблюдаемые значительные улучшения излучательных свойств диодных гетероструктур с двуслойными квантовыми ямами и ферромагнитным слоем GaMnAs в качестве инжектора могут быть обусловлены как модификацией приповерхностного слоя GaAs (возможное образование композита „углерод $+\mathrm{GaAs}^{\text {c) }}$, так и изменением свойств пленок самого графена под воздействием лазерного излучения. Очевидно, что в модифицировании пленок из МСГ на поверхности GaAs-структур определяющую роль играют два фактора: а) лазерное воздействие и б) присутствие при этом среды жидкого азота.

В работе [15] сообщается о модифицировании пленок графена, полученных с использованием графеновых чернил высокой концентрации. После воздействия в течение 1-4 ms непрерывного лазерного излучения с длиной волны $532 \mathrm{~nm}$ и плотностью мощности $5.5 \cdot 10^{7} \mathrm{~W} / \mathrm{cm}^{2}$ пленки стали более однородными, высота неровностей 
уменьшилась с 60 до $11 \mathrm{~nm}$, коэффициент пропускания на длине волны $550 \mathrm{~nm}$ возрос до $85 \%$, а слоевое сопротивление уменьшилось до $30 \mathrm{kOhm}$.

Ранее описаны применения жидкого азота для получения графена при импульсном лазерном воздействии на мишень пиролитического графита или оксида графена [16-18]. В частности, авторами $[16,18]$ предложена методика получения слоев графена с использованием наносекундного и фемтосекундного лазерного излучения для абляции мишени пиролитического графита. В обоих случаях графен получают путем расслоения графита в жидком азоте благодаря проникновению молекул азота между слоями графита и последующему испарению криогенной жидкости под воздействием лазерного излучения. Происходит расширение газофазного азота, и в результате отделяются плоскости графена. Значительного улучшения структурных и электрических свойств пластин оксида графена, помещенных в сосуд с жидким азотом, удалось достичь с использованием сканирования поверхности пикосекундным лазером [17].

С учетом указанного механизм процесса модифицирования гетеросистемы MCГ/GaAs в нашем случае может выглядеть следующим образом. МСГ, нанесенный на поверхность арсенидгаллиевых структур, представляет собой сетку из перекрывающихся нанополосок графена. Поверхность слоя GaAs, на который наносился графен, содержит неровности (среднеквадратичное отклонение может достигать $~ 5-7 \mathrm{~nm}$ по данным АСМ при толщине слоя GaMnAs 90-100 nm). Поэтому можно полагать, что почти сплошной слой МСГ при трехслойном нанесении соприкасается со слоем полупроводника в наиболее высоких точках поверхности, т. е. плотный контакт полосок графена с покровным (пассивирующим для GaMnAs) слоем GaAs отсутствует, и систему MCГ/GaAs в целом можно рассматривать как пористый материал.

Жидкий азот, используемый при измерении ФЛ, повидимому, может заполнять все имеющиеся поры, а лазерное воздействие благодаря высокой теплопроводности графена и его плохому тепловому контакту с полупроводником может приводить к активному испарению азота. Здесь необходимо отметить, что, согласно данным [19], температурная зависимость теплопроводности графита и графена является немонотонной и содержит максимум в области температур 80-100 К, причем теплопроводность графена в несколько раз превышает теплопроводность графита (это касается практически всего диапазона температур измерений - от 10 до 500 К). В результате воздействия лазерного излучения на систему MCГ/GaAs наблюдается расслоение МСГ, более массивная часть графеновых полосок отваливается, а тонкие слои графена остаются на поверхности полупроводника и/или вплавляются в нее. При этом может также происходить процесс сильного легирования углеродом покровного слоя GaAs. Кроме того, наблюдается изменение морфологии контакта MCГ/GaAs, он становиться более гладким (как видно из представленных выше исследований РЭМ).
Отметим, что в $[12,14]$ наблюдалось улучшение электрического и термического контактов между МСГ и металлом в результате воздействия непрерывного лазера.

Мы полагаем, что помимо изменения свойств самого МСГ наиболее вероятной, на наш взгляд, причиной усиления ФЛ и ЭЛ после лазерного воздействия в среде жидкого азота может быть изменение положения уровня Ферми и зонной структуры в области двуслойной квантовой ямы вследствие появления на поверхности тонкого слоя (может быть, сильнолегированного углеродом слоя $\mathrm{GaAs}$ ) с повышенной концентрацией дырок.

\section{Заключение}

Обнаружено влияние воздействия непрерывного излу-

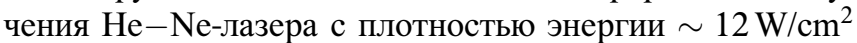
в процессе измерения ФЛ при температуре жидкого азота в течение нескольких секунд на контакт „многослойный графен/GaAs“ в диодных структурах с двуслойной квантовой ямой $\mathrm{InGaAs} / \mathrm{GaAsSb} / \mathrm{GaAs}$. Наблюдаются значительные улучшения излучательных свойств (ФЛ и ЭЛ) диодных гетероструктур, объясняемые как модификацией слоя GaAs (образование композита „углерод $\left.+\mathrm{GaAs}^{6}\right)$, так и изменением свойств пленок самого графена под воздействием лазерного излучения. Представленные результаты показывают, что светоизлучающие структуры с поверхностью, покрытой графеном, могут быть использованы для изготовления достаточно эффективных светодиодов.

Следует отметить, что описанные в настоящей работе эффекты лазерного излучения невысокой интенсивности следует принимать во внимание, поскольку при исследовании углеродных (графеновых) и гибридных структур „графен-полупроводник“ часто (при исследовании КРС или ФЛ) используется лазерное излучение, сфокусированное на небольшую площадь. Поэтому возможное воздействие инструмента на свойства структур может быть значительным.

\section{Благодарности}

Авторы выражают глубокую благадарность М.А. Канески (Center for Semiconductor Components and Nanotechnologies, UNICAMP) за помощь в получении спектров КРС изучаемых структур.

\section{Финансирование работы}

Работа выполнена при поддержке РФФИ (грант 1829-19137_мк) и при частичной поддержке гранта № 1919-00545 Российского научного фонда (изготовление структур с использованием импульсного лазерного нанесения).

\section{Конфликт интересов}

Авторы заявляют, что у них нет конфликта интересов. 


\section{Список литературы}

[1] Яблонский А.Н., Морозов С.В., Гапонова Д.М., Алешкин В.Я., Шенгуров В.Г., Звонков Б.Н., Вихрова О.В., Байдусь Н.В., Красильник 3.Ф. // ФТП. 2016. Т. 50. В. 11. C. $1455-1458$.

[2] Вихрова О.В., Данилов Ю.А., Звонков Б.Н., Демина П.Б., Дорохин М.В., Калентьева И.Л., Кудрин А.В. // ФТТ. 2017. T. 59. B. 11. C. $2196-2199$.

[3] Калентьева И.Л., Звонков Б.Н., Вихрова О.В., Данилов Ю.А., Демина П.Б., Дорохин М.В., Здоровейщев А.В. // ФТП. 2015. Т. 49. В. 11. С. $1478-1483$.

[4] Ma Y., Zhi L. // Small Methods. 2019. V. 3. P. 1800199.

[5] Shin D.H., Choi S.-H. // Micromachines. 2018. V. 9. N 7. P. 350 .

[6] Вихрова О.В., Данилов Ю.А., Демидов Е.С., Звонков Б.Н., Ковалев В.И., Кунькова З.Э., Подольский В.В., Сапожников М.В., Сучков А.И., Темирязева М.П. // Известия РАН. Сер. физ. 2007. Т. 71. В. 1. С. 37-39.

[7] Звонков Б.Н., Вихрова О.В., Данилов Ю.А., Дроздов Ю.Н., Кудрин А.В., Сапожников М.В. // ФТТ. 2010. Т. 52. В. 11. C. 2124-2127.

[8] Alaferdov A.V, Savu R., Rackauskas T.A., Rackauskas S., Canesqui M.A., de Lara D.S., Setti G.O., Joanni E., de Trindade G.M., Lima U.B., de Souza A.S., Moshkalev S.A. // Nanotechnology. 2016. V. 27. P. 375501.

[9] Alaferdov A.V., Gholamipour-Shirazi A., Canesqui M.A., Danilov Yu.A., Moshkalev S.A. // Carbon. 2017. V. 69. P. 525-535.

[10] Alaferdov A.V., Savu R., Canesqui M.A., Kopelevich Y.V., da Silva R.R., Rozhkova N.N., Pavlov D.A., Usov Yu.V, de Trindade G.M., Moshkalev S.A. // Carbon. 2018. V. 129. P. 826-829.

[11] Ferrari A.C. // Solid State Commun. 2007. V. 143. P. 47-57.

[12] Ermakov V.A., Alaferdov A.V., Vaz A.R., Baranov A.V., Moshkalev S.A. // Nanotechnology. 2013. V. 24. P. 155301.

[13] Ferrari A.C., Basko D.M. // Nature Nanotechnology. 2013. V. 3. N 4. P. 235-246.

[14] Moshkalev S.A., Ermakov V.A., Vaz A.R., Alaferdov A.V., Savu R., Silveira J.R., Souza Filho A.G. // Microelectronic Engineering. 2014. V. 121. P. 55-58.

[15] Del S.K., Bornemann R., Bablich A., Schäfer-Eberwein H., Li J., Kowald T., Östling M., Bolivar P.H., Lemme M.C. // 2D Materials. 2015. V. 2. P. 011003.

[16] Mortazavi S.Z., Parvin P., Reyhani A. // Laser Phys. Lett. 2012. V. 9. N 7. P. 547-552.

[17] Guan Y.C., Fang Y.W., Lim G.C., Zheng H.Y., Hong M.H. // Scientific Reports. 2016. V. 6. P. 28913.

[18] Abramov D., Arakelian S., Kochuev D., Makov S., Prokoshev V., Khorkov K. // Nanosystems: Physics, Chemistry, Mathematics. 2016. V. 7. N 1. P. 220-225.

[19] Елецкий А.В., Искандарова И.М., Книжник А.А., Красиков Д.Н. // УФН. 2011. Т. 181. В. 3. С. 233-268. 